\section{Wiederholbedingung von Messungen}

C. Vidal ${ }^{1}$ und W.-R. Külpmann ${ }^{2}$

${ }^{1}$ Landeskriminalamt Niedersachsen, Dezernat 53 „Chemie“, Hannover, Deutschland

${ }^{2}$ Hannover, Deutschland

Englischer Begriff repeatability condition of measurement; repeatability condition

Definition Messbedingung aus einer Menge von Bedingungen, die dasselbe $\triangleright$ Messverfahren, dieselben Bediener, das- selbe Messsystem, dieselben Betriebsbedingungen und denselben Ort und wiederholte Messungen (s. \ Messung) an demselben Objekt oder an ähnlichen Objekten während eines kurzen Zeitintervalls umfassen (Brinkmann 2012). Für Anmerkungen s. Literatur.

\section{Literatur}

Brinkmann B (2012) Internationales Wörterbuch der Metrologie (VIM) Deutsch-englische Fassung. ISO/IEC-Leitfaden 99:2007, 4. Aufl. Beuth-Verlag, Berlin 